\title{
Development of an Improved Tracheal Explant Bioassay for the Detection of the Ciliary Dyskinesia Factor in Cystic Fibrosis Serum
}

\author{
MICHAEL G. GABRIDGE, ${ }^{(26)}$ MARLENE J. BRIGHT, C. COE AGEE, JOHN M. NICKERSON, AND \\ NANINE S. HENDERSON \\ Department of Microbiology, School of Basic Medical Sciences, University of Illinois, Urbana, Illinois; Department of \\ Biochemistry, University of Tennessee Center for the Health Sciences, Memphis, Tennessee; and Department of \\ Anatomy, School of Human Medicine, Michigan State University, East Lansing, Michigan, USA
}

\begin{abstract}
Summary
A tracheal ring explant system, when used with $25 \%$ cystic fibrosis (CF) serum, displayed obvious ciliostasis. Hamster, rabbit, and guinea pig explants all had measurable decreases in ciliary activity after $24 \mathrm{hr}$ of incubation in the serum. The differential response to $\mathrm{CF}$ serum (relative to normal serum) was greatly increased by using explants which were maintained 24-72 hr in unimal essential medium (MEM) with $10 \%$ horse serum and which were selected on the basis of optimal ciliary activity and vigor. With such a bioassay system of guinea pig tracheal explants, incubation with $25 \%$ normal serum would produce essentially no change in relative ciliary activity (score of 242 of a possible 300 ), whereas $C F$ serum resulted in an $86 \%$ decrease (score of 33 ). Scanning electron microscopic observation indicated that the explants displaying the $\mathrm{CF}$-ciliostatic effect had significant accumulations of mucous over the ciliated epithelial surface. A biochemical viability assay (dehydrogenase activity) showed no cytonecrosis when $C F$ serum-treated tissues were compared to standard explants $(10 \%$ horse serum in MEM) or control explants (25\% normal human serum).
\end{abstract}

\section{Speculation}

Cystic fibrosis serum, when tested at $25 \%$ concentrations on preselected guinea pig tracheal ring cultures, showed an obvious and easily measurable ciliostatic response. This new bioassay may serve as an improved model to detect and analyze the CF dyskinesia factor.

$\mathrm{CF}$, the most common lethal genetic disease among Caucasians, affects a variety of organ systems through unknown mechanisms $(20,22)$. Interference with the normal functioning of exocrine glands (primarily the pancreas) and of normal mucociliary clearance invariably leads to complications involving the digestive and respiratory tracts $(7,13)$. Some insight into this latter phenomenon was gained when Spock et al. (21) noted that the serum of CF homozygotes contained a factor which altered the coordination of ciliary motion in rabbit tracheal explants. This ciliary dyskinesia factor appears to be a low molecular weight protein which binds noncovalently to $\gamma$-globulins $(5,6)$. It is found in serum and other body fluids of CF patients and is also produced in fibroblast and leukocyte cultures derived from such patients. Both the coordination and the frequency of ciliary beating appear to be affected.

Presence of the dyskinesia factor has been suggested for use as an indicator for the identification of CF homozygotes (patients) and heterozygotes (carriers) $(1,4,11,12,14)$. Full realization of this potential, as well as determination of the role of dyskinesia in the pathogenesis of CF disease and its complications, must await the development of more reliable and accurate indicators of ciliary dyskinesia, as well as a better understanding of the basic effect. For example, there is controversy as to whether or not dyskinesia involves a true ciliostasis, discoordination, or cytonecrosis of ciliated cells, or whether it is simply a physical response to altered mucous production $(3,9,10)$. As most commonly employed, the dyskinesia assay uses mammalian (rabbit) trachea and involves short-term culture and exposure of mucosal fragments to high concentrations of serum diluted in tissue culture media. Although significant improvements toward standardization have been instituted $(4,11,12)$, the manipulation and scoring of the mucosal sheets remain cumbersome and are probably the source of many reported discrepancies. Tracheal ring organ, or explant, cultures have been used extensively in infectious diseases $(8,15)$ and have advantages in ease of preparation and quantitation $(15,18,19)$. We employed the explant model system with hamster, rabbit, and guinea pig tissue in an attempt to: 1) evaluate the utility of tracheal slices for detecting CF-related alterations in ciliary activity, and 2) biochemically assess the extent of cytotoxicity in CF-treated organ cultures.

\section{MATERIALS AND METHODS}

\section{SERUM SAMPLES}

Blood samples were obtained from CF patients and normal (i.e., non-CF) controls by aseptic venipuncture of volunteers at several clinics in southeastern Michigan. Serum was separated by standard clinical methods, and 1- to 2-ml aliquots were frozen at $-70^{\circ}$ until use. In certain experiments, control serum (human, pooled) was purchased from International Scientific Industries, Cary, IL. For use, samples were thawed at $37^{\circ}$, diluted with organ culture medium to provide 25 to $50 \%$ serum to medium mixtures, and were applied immediately to the explants.

\section{EXPLANTS}

Hamsters (125 g, male, Golden Syrian) were obtained from Engle Laboratories, Farmersberg, IN, and rabbits (1-2 kg, of mixed breed and sex) were obtained locally. Guinea pigs ( $200 \mathrm{~g}$, female, Crl, COBS/HA) were obtained from Charles River Breeding Laboratories, Wilmington, MA, as were rats (125 g, female, Crl, COBS LE/BR). Animals were anesthetized with sodium pentobarbital, tracheas were removed aseptically, and organ cultures were prepared as described $(15,17)$. Explants consisted of 1- to 2-mm thick transverse slices of trachea, the inner aspects of which were lined with ciliated epithelium. Cultures were maintained in petri dishes in a thin layer (e.g., $0.7 \mathrm{ml} / 35-\mathrm{mm}$ dish) of MEM (autoclavable, with spinner salts; GIBCO, Grand Island, NY) complete with glutamine and sodium bicarbonate and sup- 
plemented with horse serum (10\%) and penicillin $\mathrm{G}(500 \mathrm{U} / \mathrm{ml})$. $\mathrm{CF}$ and normal serum dilutions were made in organ culture medium without any horse serum, and were tested with three to five explants per sample.

\section{ASSAYS}

Relative ciliary activity $(15,17)$ was determined during observation of the ciliated layer with phase optics $(225 \mathrm{X})$. The relative ciliary activity is the product of the percent of the surface remaining intact $(0-100 \%)$ and the subjective vigor of ciliary beating $(0-3+)$. The dehydrogenase assay has been described (19) and consists of anaerobic tissue incubation in the presence of a sodium succinate and 2,3,5-triphenyltetrazolium chloride mixture, followed by formazan extraction in acetone and spectrophotometric quantitation at $490 \mathrm{~nm}$. Dry weight values were determined on a Perkin-Elmer electrobalance after dehydration of specimens in vacuo over a bed of silica gel for at least $24 \mathrm{hr}$.

\section{ELECTRON MICROSCOPY}

Tracheal rings were rinsed briefly in phosphate-buffered saline ( $\mathrm{pH} 7.4$ ) and were then fixed in $3 \%$ glutaraldehyde in phosphatebuffered saline (overnight at $4^{\circ}$ ). Dehydration was accomplished with a graded ethanol water series (10-100\%). Specimens were dried according to the critical point method (liquid $\mathrm{CO}_{2}$ ) before being coated with gold-palladium and being examined in a JEOL JSM-U3 or a Zeiss Novascan scanning electron microscope.

\section{RESULTS}

Preliminary experiments with hamster and rabbit tracheal ring cultures indicated that the standard $50 \%$ serum treatment often induced some ciliostasis in both the CF and normal serum samples. In an attempt to maximize the CF to control differential, the serum concentration was reduced from the standard $50 \%$ to $25 \%$, and new laboratory animal species were tested. Rat tracheal explants showed little difference in response to the CF or control sera, whereas rabbit tissue exposed to CF serum had a relative ciliary activity value of approximately half of the control values. Even more significantly, guinea pig tracheal rings incubated in $25 \%$ control serum had a relative activity reading of 150 , whereas CF-treated rings had no measurable ciliary motion.

In order to verify this observation, large numbers of tracheal ring explants were established and evaluated with several serum samples. The comparative data from 164 explant cultures is given in Table 1. The relative ciliary activity measurements (the product of the percent of the ring with an intact, ciliated surface, times the relative vigor of beating; maximum score of 300 ) from $25 \%$ control or CF serum-treated rings show definite CF effects. Hamster tissue showed minor differences after $1 \mathrm{hr}$, but relative activity fell to $15 \%$ of the control level at $24 \mathrm{hr}$. Rabbit tissue displayed an early response (32\% decrease) at $1 \mathrm{hr}$, but after $24 \mathrm{hr}$ the differential was only approximately $50 \%$, due primarily to degradation in the controls. Guinea pig tissue was superior because at $1 \mathrm{hr}$ the CF tissue was clearly affected to a greater degree than its controls, and at $24 \mathrm{hr}$ the differential was even more significant. CF serum had more obvious ciliostatic effects on guinea pig trachea than on any of the other laboratory animals tested (rabbit, hamster, and rat).

A retrospective analysis of our tracheal organ culture studies with cystic fibrosis sera indicated that the differential in ciliostasis between control and CF serum treatments could have been subject to artificially low values due to spontaneous degeneration or damage in control tissues. In an attempt to minimize this type of artifact, we conducted a study which utilized "aged" rings, that is, tracheal slices which had been maintained in MEM with $10 \%$ horse serum for 24-72 hr. Only rings which appeared to be free of mucous and debris and which had an intact, vigorously beating ciliated epithelium were used. Readings of relative ciliary activity were made at 1 - and $24-\mathrm{hr}$ post-treatment with either $25 \%$ normal or CF serum. The results (Fig. 1) demonstrate the utility of this

Table 1. Comparison of various animal tracheal explants relative to sensitivity to the CF serum ciliostasis effect

\begin{tabular}{clccr}
\hline Species & Serum $^{2}$ & \multicolumn{3}{c}{ Mean relative ciliary activity $( \pm$ SEM) } \\
\cline { 3 - 5 } & & $\mathrm{t}=0$ & $\mathrm{t}=1 \mathrm{hr}$ & $\mathrm{t}=24 \mathrm{hr}$ \\
\hline Hamster (34) & $\mathrm{N}$ & $237 \pm 2$ & $234 \pm 3$ & $241 \pm 4$ \\
& $\mathrm{CF}$ & $243 \pm 2$ & $205 \pm 8$ & $35 \pm 10$ \\
Rabbit (26) & $\mathrm{N}$ & $249 \pm 5$ & $249 \pm 5$ & $137 \pm 16$ \\
& $\mathrm{CF}$ & $255 \pm 5$ & $170 \pm 20$ & $76 \pm 17$ \\
Guinea pig (22) & $\mathrm{N}$ & $234 \pm 2$ & $231 \pm 4$ & $175 \pm 12$ \\
& $\mathrm{CF}$ & $243 \pm 3$ & $120 \pm 12$ & $5 \pm 2$ \\
\hline
\end{tabular}

${ }^{1}$ Tracheal explant source; number of explants in parentheses.

${ }^{2} \mathrm{~N}=$ normal; $\mathrm{CF}=$ cystic fibrosis serum; both $25 \%$ in MEM. Assays are based on 3-5 explants per serum sample; mean data from 6-10 different serum samples for each category.

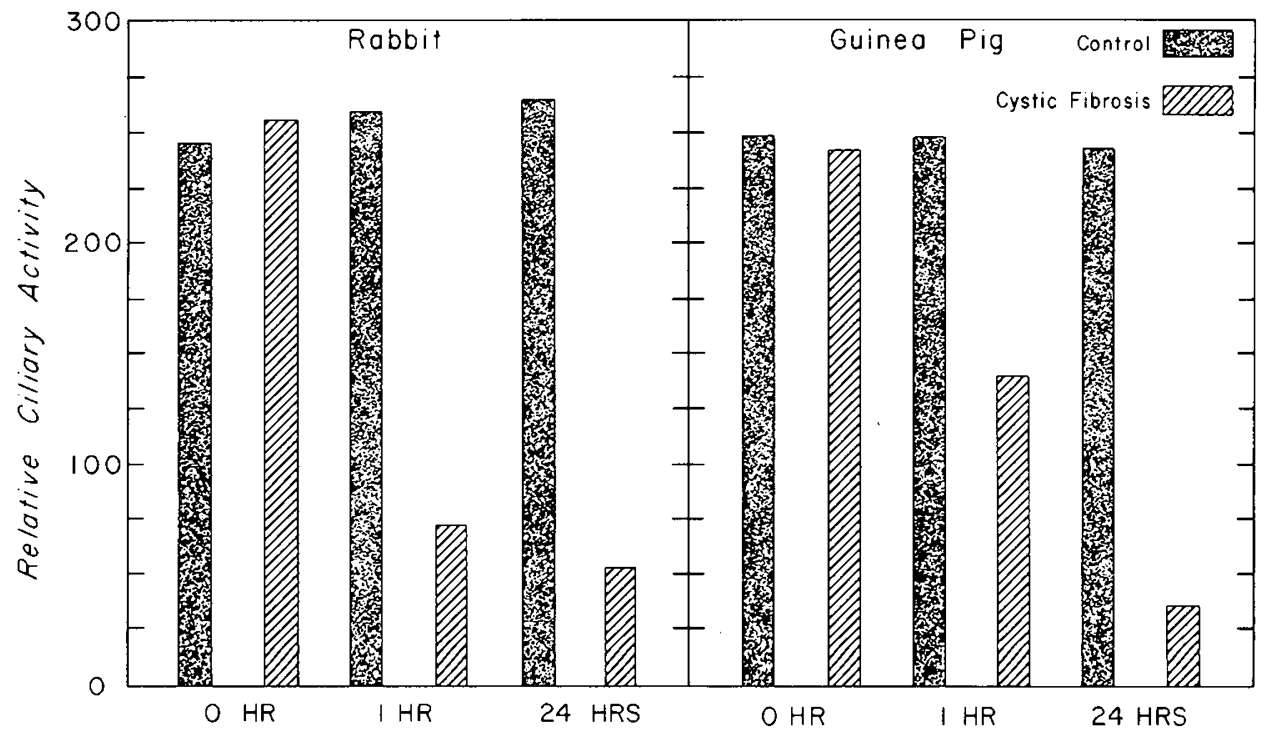

Fig. 1. Effect of CF or normal human serum (25\%) on tracheal explants selected after $24-72 \mathrm{hr}$ of cultivation in vitro. Mean data from 21 rabbit explants and 36 guinea pig explants with 3 explants per serum sample. 

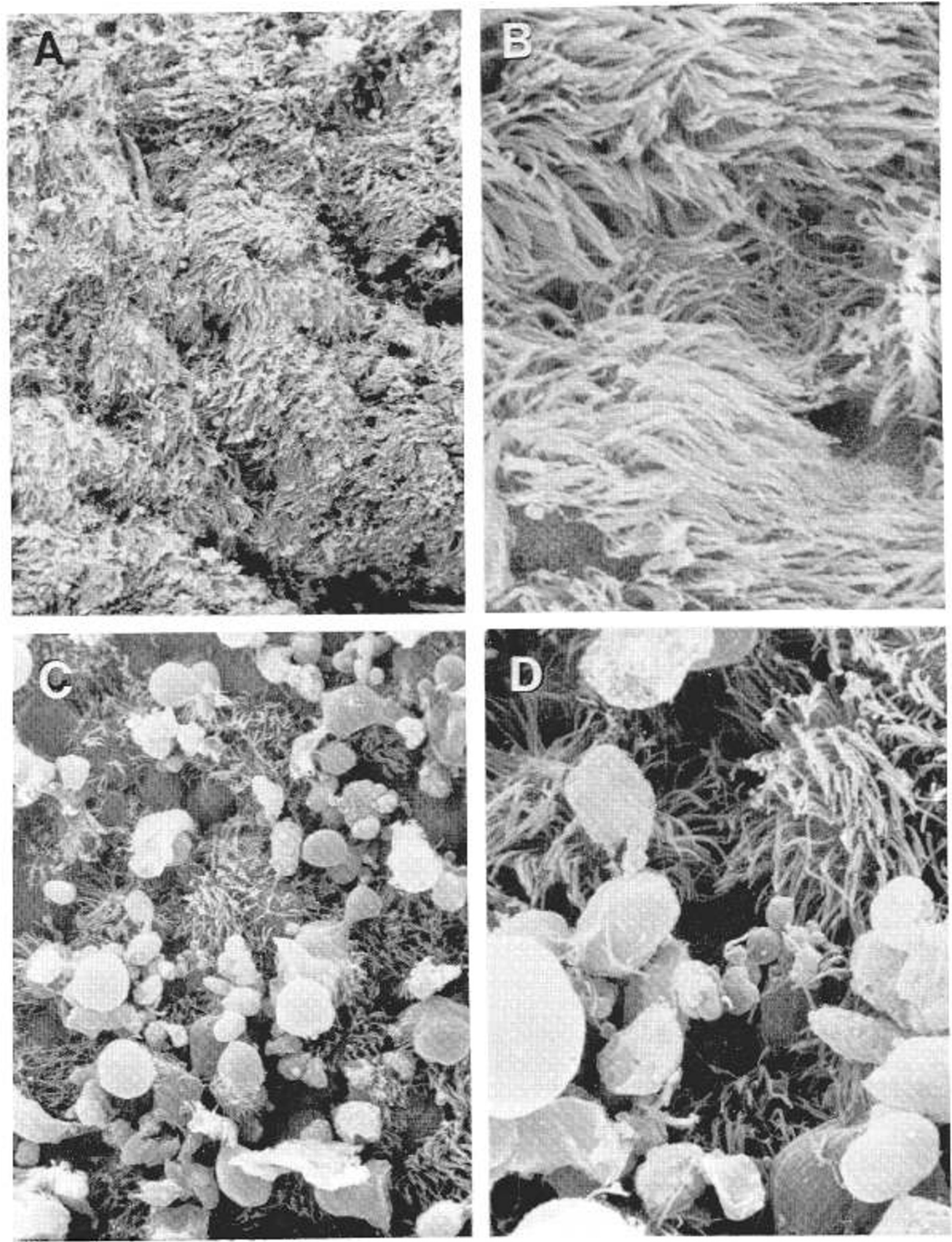

Fig. 2. Scanning electron micrographs of the mucous production observed after incubation of guinea pig tracheal explants in $25 \% \mathrm{CF}$ serum. $A$ and $B$, normal human serum; $C$ and $D, C F$ serum. Micrographs $A$ and $C, \times 1000 ; B$ and $D, \times 3000$.

approach. The use of aged tracheal rings resulted in the maintenance of high (approximately $250 / 300$ ) relative activity values in normal serum treated explants, whereas CF-treated explants had significantly decreased values. For rabbit tissue, the l-hr values were $258 \pm 5$ (SEM) and $71 \pm 18$ for normal and CF sera, respectively. At $24 \mathrm{hr}$, the same groups had values of $264 \pm 6$ and $51 \pm 19$ for their relative ciliary activity readings.

The response in guinea pig tissue was slower, but reached a greater differential after 1-day post-treatment. Treated guinea pig tissues also had smaller deviations from the mean throughout the treatment period. The $1-\mathrm{hr}$ readings of relative ciliary activity were $246 \pm 3$ and $138 \pm 9$ for control and CF sera, and these were $242 \pm 4$ and $33 \pm 5$ at $24 \mathrm{hr}$. Explant cultures of guinea pig trachea thus responded to the $25 \% \mathrm{CF}$ serum exposure with a $44 \%$ decrease in ciliary motion within the 1-hr, and an $86 \%$ decrease by $24 \mathrm{hr}$.

Scanning electron microscopy of these guinea pig tissues revealed that ciliostasis was consistently concomitant with a significant degree of mucous exudation (Fig. 2). Mucous globules were 
Table 2. Effect of $C F$ and normal serum on dehydroogenase levels in guinea pig tracheal ring cultures

\begin{tabular}{rccc}
\hline \multirow{2}{*}{$\begin{array}{c}\text { Time } \\
(\mathrm{hr})\end{array}$} & \multicolumn{3}{c}{ Dehydrogenase activity } \\
\cline { 2 - 4 } & $\begin{array}{c}\text { Horse serum } \\
(10 \%)\end{array}$ & $\begin{array}{c}\text { Normal human } \\
\text { serum }(25 \%)\end{array}$ & $\begin{array}{c}\text { CF serum } \\
(25 \%)\end{array}$ \\
\hline 1 & $0.667 \pm 0.031$ & $0.686 \pm 0.039$ & $0.760 \pm 0.045$ \\
24 & $0.612 \pm 0.039$ & $0.790 \pm 0.038$ & $0.657 \pm 0.032$ \\
\hline
\end{tabular}

' Specific activity as OD $490 / \mathrm{mg}$ dry wt; mean data \pm SEM from four separate experiments with total of $14-16$ replicates for the four sera.

evident over the majority of epithelial surfaces when tracheal explants were exposed to CF serum. Control serum, at the same concentration ( $25 \%$ in MEM) and time period ( $24 \mathrm{hr}$ ), produced minimal increases in mucous production. Neither control nor CF serum produced visual damage similar to that observed in the cases of Mycoplasma pneumoniae infection of explants.

In order to determine whether the mucous production in this bioassay was related to the cause of ciliostasis or was simply a response to necrosis, another series of experiments examined viability levels in explants. Cellular dehydrogenase assays were conducted on guinea pig tracheal ring explants exposed to either normal human serum $(25 \%)$, CF serum $(25 \%)$, or horse serum (10\%, normal method control). Data from 276 explants (three tracheal rings per dehydrogenase assay) are shown in Table 2 . It can be seen that at $\mathbf{l ~ h r}$ the dehydrogenase activity of both normal human and $\mathrm{CF}$ serum-treated $(25 \%)$ explants are above the control (10\% horse serum) tracheal ring values. After $24 \mathrm{hr}$ of incubation, the levels were still slightly higher, indicating no measurable cytonecrosis for either serum treatment in these assays, in spite of the significant ciliostasis and mucous production in the tracheal ring explants exposed to $C F$ serum.

\section{DISCUSSION}

The identification and analysis of the CF ciliary dyskinesia factor have been based on the biological response observed in various model systems. The development of a reliable, sensitive, and easily reproducible bioassay appears to be critical for exploitation of the cilia effect into a test to detect the factor(s), and to identify heterozygotes and homozygotes.

The rabbit tracheal mucosa model has been improved $(4,11$, 12 ), and new models such as ciliated oyster gill (3) and larval brine shrimp (2) have been developed. Unfortunately, each of these assays has inherent disadvantages $(13,20)$ which have lead some investigators to question the utility of dyskinesia assays in the detection of CF homozygotes and heterozygotes. In an attempt to develop an improved bioassay for the CF factor, we utilized tracheal ring explants in which ciliary motion (observed along the inner, vertical surface of a 1 - to $2-\mathrm{mm}$ tracheal slice) could be quantitated visually. This culture system has been used with various biochemical $(16,18,19)$ assays of viability, so there are standardized subjective and objective techniques available to measure necrosis. High concentrations of human serum (e.g., 50\%) on explants caused little differential response in ciliary activity between control serum and CF serum, and no cytonecrosis was detectable. However, the use of $25 \%$ serum and the deployment of tracheal rings preselected for active ciliary motion results in significant ciliostasis in the presence of CF serum, and not in the presence of normal serum. This system gave improved responses especially prominent with rabbit and guinea pig tissue. We found that guinea pig tracheal explants had a more significant and less variable ciliostatic response than rabbit tissue. Given this differential, plus the greater ease of handling, the ability to quickly prepare large numbers of explants, and the low maintenance costs, quinea pigs would appear to have definite potential to serve as convenient sources of ciliated tissue for CF studies.

Electron microscopic examination of guinea pig explants showed that normal human serum (25\% in MEM) produced little change in the explants after $24 \mathrm{hr}$. However, CF serum produced massive outpourings of mucous, such that the epithelial surface was coated with mucous globules. The mucous exudation was the most likely cause of the ciliostatic response because no actual necrosis was detectable in the treated explants with the dehydrogenase assay.

Our findings of an absence of direct toxic effects on ciliated epithelial cells, in conjunction with an overproduction and/or oversecretion of mucous, are consistent with the data of Cheung and Jahn $(9,10)$. They used high speed cinematographic analysis of tracheal beat patterns and concluded that CF serum did not affect cilia directly, but instead affected the mucous and gave rise to hydrodynamic phenomenon of stagnation. Although they concluded that this could be a reflection of cytonecrosis, our techniques could not reveal any preferential cell death due to the CF serum. Our data are in agreement with the findings of Baur et al. (3), who used electron microscopy of serum-treated oyster gill cilia and concluded that dyskinesia or ciliostasis was most probably related to abnormal mucous production and release. We have also verified the observation of Yeates et al. (23). They used rabbit tracheal explants and found that CF sera induced a discharge of mucous material, which led to dyskinesia and a loss of ciliary activity.

Collectively, our data indicate that a bioassay system based on the use of selected guinea pig tracheal ring explants exposed to $25 \%$ concentrations of human serum for $24 \mathrm{hr}$ may constitute an improved model for the study of the CF dyskinesia factor. Now that the system has been developed, it can be used in extensive double blind studies in order to determine its utility in the identification of cystic fibrosis patients and carriers.

\section{CONCLUSION}

A tracheal ring (transverse slice) organ culture assay, based on the use of guinea pig explants preselected for optimal ciliary activity and their subsequent incubation in $25 \% \mathrm{CF}$ serum, proved valuable for the detection of CF-specific ciliostatic activity. Significant accumulations of mucous, with no biochemical evidence of cytonecrosis, were associated with the CF serum treatment; little or no changes were noted with control sera. The guinea pig tracheal ring assay appears to offer definite advantages for the detection of the CF dyskinesia factor(s).

\section{REFERENCES AND NOTES}

1. Arad, I., Lafair, J. S.. and Shapira. E.: Application of cilia dyskinesia test in the diagnosis of cystic fibrosis in an adolescent. Israel J. Med. Sci.. 11: 10 (1975).

2. Bargman. G. J.: Larval brine shrimp (Nauplii): A potentially useful model to study cystic fibrosis. Tex. Rep. Biol. Med.. 34: 37 (1976).

3. Baur. P. S., Brinkley, B. R.. and Bowman. B. H.: Effects of cystic fibrosis serum ciliary inhibitor on oyster gill ultrastructure: Analysis by scanning and transmission electron microscopy. Tex. Rep. Biol. Med.. 34: 155 (1976).

4. Beratis, N. G.. Conover. J. H.. Conod. E. J.. Bonforte. R. J.. and Hirschhorn. K. Studies on ciliary dyskinesia factor in cystic fibrosis. III. Skin fibroblasts and cultured amniotic fluid cells. Petiatr. Res.. 7: 958 (1973).

5. Bowman. B. H.: Minireview: Current biochemical approaches in cystic fibrosis research. Life Sci.. 19: 1289 (1976).

6. Bowman. B. H.. Lankford. B. J.. Fuller. G. M.. Carson. S. D.. Kurosky. A.. and Barnett. D. R.: Cystic fibrosis: The ciliary inhibitor is a small polypeptide associated with immunoglobulin G. Biochem. Biophys. Res. Commun.. 64: 1311 (1975).

7. Changus. J. E.. and Pitot. H. C.: Cystic fibrosis: A dilemma in the metabolic pathogenesis of genetic disease. Arch. Pathol. Lab. Med.. 100: 7 (1976).

8. Cherry. J. D.. and Taylor-Robinson. D.: Mycoplasma pathogenicity studies in organ cultures. Ann. N.Y. Acad. Sci.. 225: 290 (1973).

9. Cheung. A. T. W.. and Jahn. T. L.: High speed cinemicrographic studies on rabbit tracheal (ciliated) epithelia: Cytolytic effect of cystic fibrosis serum on tracheal epithelial cells. Pediatr. Res.. 10: 144 (1976).

10. Cheung. A. T. W.. and Jahn. T. L.: High speed cinemicrographic studies on rabbit tracheal (ciliated) epithelia: Determination of the beat pattern of tracheal cilia. Pediatr. Res.. 10: 140 (1976).

11. Conover, J. H.. Beratis, N. G.. Conod. E. J., Ainbender. E.. and Hirschhorn. K.: Studies on ciliary dyskinesia factor in cystic fibrosis. II. Short term leukocyte cultures and long term lymphoid lines. Pediatr. Res.. 7: 224 (1973).

12. Conover, J. H.. Bonforte. R. J.. Hathaway, P.. Paciuc. S.. Conod. E. J.. Hirschhorn, K.. and Kopel. F. B.: Studies on ciliary dyskinesia factor in cystic fibrosis. I. Bioassay and heterozygote detection in serum. Pediatr. Res.. 7: 220 (1973) 
13. Di Sant'Agnese. P. A.. and Davis. P. B.: Research in cystic fibrosis. N. Engl. J. Med.. 295: 481. 534. 597 (1976).

14. Forstner, G., Crozier, D. N., and Sturgess, J. M.: Cystic fibrosis: Present status and future prospects in detection of patients and carriers. Can. Med. Assoc. J., 113: 550 (1975).

15. Gabridge. M. G.: Hamster trachea organ cultures. In: V. Evans. V. Perry. and $M$ Vincent: Tissue Culture Association Manual. Vol. 1. p. 75-80 (Tissue Culture Association. Rockville. MD. 1976).

16. Gabridge. M. G.: Microrespirometer chamber for determinations of viability in cell and organ cultures. J. Clin. Microbiol.. 3: 560 (1976).

17. Gabridge, M. G.. Cameron, A. M., and Johnson, C. K.: Cytotoxicity of Mycoplasma pneumoniae membranes. Infect. Immun., 10: 1127 (1974).

18. Gabridge. M. G.. and Polisky. R. B.: Intracellular levels of adenosine triphosphate in hamster trachea organ cultures exposed to Mycoplasma pneumoniae cells or membranes. In Vitro. 13: 510 (1977).

19. Gabridge. M. G.. and Polisky, R. B.: Quantitative reduction of 2.3.4-triphenyltetrazolium chloride by hamster trachea organ cultures: Effects of Mycoplasma pneumoniae cells and membranes. Infect. Immun.. 13: 84 (1976).

20. Polley. M. J., and Bearn. A. G.: Cystic fibrosis: Current concepts. J. Med. Genet., 11: 249 (1974).

Copyright $\odot 1979$ International Pediatric Research Foundation, Inc. $0031-3998 / 79 / 1301-0031 \$ 02.00 / 0$
21. Spock, A., Heick. H. M. C.. Cress, H.. and Logan. W. S.: Abnormal serum factor in patients with cystic fibrosis of the pancreas. Pediatr. Res.. 1: 173 (1967).

22. Wood, R. E., Boat, T. F., and Doershuk, C. F.: Cystic fibrosis: State of the art. Am. Rev. Respir. Dis., 113: 833 (1976).

23. Yeates. D. B., Sturgess. J. M., Kahn. S. R., Levison. H.. and Aspin. N. Mucociliary transport in trachea of patients with cystic fibrosis. Arch. Dis. Child.. 51: 28 (1976).

24. The authors thank D. B. Stahl and R. B. Polisky for their expert technical assistance. Electron microscopy facilities were placed at the authors' disposal through the courtesy and cooperation of Dr. R. MacLeod (University of Illinois Center for Electron Microscopy) and Dr. Lewis Coons (Memphis State University Center for Electron Microscopy).

25. This research was supported by a grant from the Cystic Fibrosis Foundation, and by Public Health Service grant AI 12559 from the National Institute of Allergy and Infectious Diseases.

26. Requests for reprints should be addressed to: Dr. M. G. Gabridge, Department of Microbiology, 131 Burrill Hall, University of Illinois, Urbana, IL 61801 (USA).

27. Received for publication August 29, 1977.

28. Accepted for publication March 2, 1978. 